\title{
Effects of continuous and pulse irrigation with different nitrogen applications on soil moisture, nitrogen transport and accumulation in root systems
}

\author{
Lingmiao Huang, Peiling Yang*, Shumei Ren, Haobo Cui \\ (College of Water Resources and Civil Engineering, China Agricultural University, Beijing 100083, China)
}

\begin{abstract}
Pulse and continuous irrigation can affect water distribution in the soil, thereby affecting the growth and distribution of root systems. Different base and topdressing fertilizers can affect nitrogen transport in the soil and root distribution, thus affecting root water and nitrogen uptake. This study used pot experiments to set up four different nitrogen levels, including two different irrigation methods, to research the effects of soil moisture, nitrogen transport, nitrogen accumulation and root systems under the conditions of continuous and pulse irrigation, as well as different nitrogen applications. Result showed that continuous irrigation can increase the moisture content around the drip emitter position and reduce the soil moisture content in the horizontal spreading compared with pulse irrigation, especially reducing the horizontal spreading in the deep soil layers. One treatment in this study did not apply base fertilizer, and then supply topdressing fertilizer at a ratio of 2:4:4 in the seedling stage, jointing stage and tasseling stage, respectively. This treatment is beneficial for improving nitrogen utilization efficiency. Furthermore, this treatment can increase the root length density and root surface area in the deep soil layers, especially in the 20-35 cm soil depth, and to some extent increase the deep growth of the root system.
\end{abstract}

Keywords: pulse irrigation, continuous irrigation, fertilization, irrigation, soil

DOI: $10.25165 /$ j.ijabe.20181105.3674

Citation: Huang L M, Yang P L, Ren S M, Cui H B. Effects of continuous and pulse irrigation with different nitrogen applications on soil moisture, nitrogen transport and accumulation in root systems. Int J Agric \& Biol Eng, 2018; 11(5): 139-149.

\section{Introduction}

Water shortage is a worldwide problem that directly threatens global food security. China is a large agricultural country where the problem of agricultural water shortage is particularly prominent. At present, the effective irrigation area is $65873 \mathrm{hm}^{2}$, which represents approximately $48.7 \%$ of the total cultivated area in China. The water-saving irrigation area is $31060 \mathrm{hm}^{2}$. Drip irrigation can apply water both precisely and uniformly compared with furrow and sprinkler irrigation, resulting in the potential to reduce subsurface drainage, control soil salinity, and increase yield $^{[1]}$. Drip irrigation is more effective and less expensive if a large amount of soil can be wetted with each emitter without losing water or nutrients below the root zone ${ }^{[2]}$, and has become a common irrigation method that widely used in corn, tomato, cucumber, green pepper and other crops.

The water movement is completely dependent on the variation in the total hydraulic potential from one layer to the other within the soil profile ${ }^{[3]}$. However, while almost all subsurface drip emitter flow amounts are approximately $1.1-2.0 \mathrm{~L} / \mathrm{h}$, the actual supply is greater than the actual amount of water that the plants need, producing inevitable leakage losses. A more scientific approach is to provide a continuous, small amount of water to roots

\section{Received date: 2018-01-19 Accepted date: 2018-06-05}

Biographies: Lingmiao Huang, PhD candidate, research interests :irrigation method and technology, Email: huanglingmiao89@126.com; Shumei Ren, Professor, research interests: irrigation method and technology, Email: renshumei@126.com ; Haobo Cui, Master, research interests: irrigation method and technology, Email: yinhexizhan@163.com

*Corresponding author: Peiling Yang, $\mathrm{PhD}$, Professor, research interests: irrigation method and technology, College of Water Resources and Civil Engineering, China Agricultural University, 17 Qinghua East Road, Haidian District, Beijing 100083, China. Tel: +86-10-62737866, Email: yangpeiling@, 126.com. to meet the water demands of plants, while reducing leakage losses. In pulse flow, the wetted width increased, and the wetted depth decreased, while the on-time decreased for the same amount of applied water volume ${ }^{[4]}$. Pulsing and lower application rates produced minor increases in horizontal spreading at the end of water application. Furthermore, higher antecedent water content increased the water spreading from drip irrigation systems, but the increases were greater in the vertical direction than in the horizontal ${ }^{[2]}$. A higher leaching fraction $(6.4 \%-43.1 \%)$ was recorded in pulse irrigation compared to continuous (1.1\%-35.1\%) irrigation with the same amount of applied water, which was brought about by the variation in initial soil water content and time of irrigation application ${ }^{[5]}$. The distribution of soil water in pulse and continuous irrigation under the condition of no root was studied. However, the effects of pulse and continuous irrigation on soil moisture distribution under the condition of root system require further study.

The supply of nitrogen $(\mathrm{N})$ is as important as water for crop production. Maize has a positive response to $\mathrm{N}$ fertilizer application ${ }^{[6]}$. Water and $\mathrm{N}$ deficit lead to reductions in crop production by reducing resource utilization efficiency. Furthermore, an interaction between $\mathrm{N}$ and water supply has been demonstrated. In an other words, $\mathrm{N}$ uptake from soil is influenced by water supply ${ }^{[7]}$. At low $\mathrm{N}$ availability, $\mathrm{N}$ demand for maximum plant-growth rate is not matched by plant $\mathrm{N}$ uptake. To acquire adequate $\mathrm{N}$, plants may increase root length density to explore a larger soil volume and/or increase $\mathrm{N}$-uptake activity ${ }^{[9]}$. Therefore, an optimum amount of $\mathrm{N}$, based on the available amount of water, is needed to improve crop yield ${ }^{[8]}$. Across the $\mathrm{N}$-fertilization rates, full irrigation plants accumulated significantly greater amounts of $\mathrm{N}$ than deficit irrigation treatments ${ }^{[10]}$. Further research is needed to explore the effect of $\mathrm{N}$ transport in pulse and continuous irrigation conditions, as well as the impact of different base and topdressing fertilizers in continuous irrigation on $\mathrm{N}$ 
transport.

Root growth and development can affect $\mathrm{N}$ uptake. On the other hand, $\mathrm{N}$ additions may affect corn (Zea mays L.) root growth $^{[11]}$. While $\mathrm{N}$ accumulation, dry matter production and yield formation have increased, the efficiency of roots in acquiring $\mathrm{N}$ has increased to match the requirement of $\mathrm{N}$ accumulation for plant growth and yield formation ${ }^{[12]}$. Characteristic parameters of summer maize root at the filling stage increased and then decreased along with the improvement of $\mathrm{N}$ application rates for both of the $\mathrm{N}$ fertilizers. Furthermore, in regard to conditions of the pot experiment the first branch of roots (diameter $<1.00 \mathrm{~mm}$ ) was the main area of root absorption of water and fertilizer ${ }^{[13]}$. Meanwhile, under the alternative furrow irrigation and conventional $\mathrm{N}$-supply, the root length of the plant was larger in north, south and beneath the canopy in the soil layer of $0-100 \mathrm{~cm}$. Total root length and root surface area at the filling stage were also larger ${ }^{[14]}$. The maize root length density in the $30-60 \mathrm{~cm}$ layer was three times greater in the treatments with $\mathrm{N}$ and $\mathrm{P}$ fertilizers than with $\mathrm{N}$ fertilizer only. Manure addition increased maize yield by $50 \%$ and $\mathrm{N}$ uptake by $43 \%$ and reduced $\mathrm{N}_{\text {min }}$ (mostly $\mathrm{NO}_{3}-\mathrm{N}$ ) accumulation in the soil by $46 \%{ }^{[15]}$. N stimulated root length in the area of application without affecting total root length ${ }^{[11]}$. Root growth was affected by both water and nitrogen. No other studies have examined the effect of continuous irrigation on maize root growth. This study focuses on maize root length density and root surface area under the conditions of continuous irrigation methods and $\mathrm{N}$ levels.

\section{Materials and methods}

\subsection{Pot filling}

The experiment was conducted in a greenhouse at the Tongzhou Experimental Station $\left(39^{\circ} 43^{\prime} \mathrm{N}, 116^{\circ} 41^{\prime} \mathrm{E}\right.$, altitude
$23.73 \mathrm{~m}$ ) of China Agricultural University, Beijing, China. The area has a typical semi-arid temperate continental monsoon climate characterized by cool dry winters and hot wet summers. It is rich in sunlight with a mean annual sunshine duration of $2459 \mathrm{~h}$ and average annual temperature of $11.4^{\circ} \mathrm{C}-12.4^{\circ} \mathrm{C}$. The average annual precipitation is $565 \mathrm{~mm}$, the mean annual evaporation is $1140 \mathrm{~mm}$ and the ground water table is about $25.75 \mathrm{~m}$ below the ground surface. The experimental period was from April to September. Each pot consisted of a bowl with a diameter of $30 \mathrm{~cm}$ and a height of $45 \mathrm{~cm}$. The soil was obtained from $0-30 \mathrm{~cm}$ surface soil in the greenhouse, dried outdoors until the soil moisture was approximately $0.1 \%$ before used in experiment. The soil was then sieved with a $2 \mathrm{~mm}$ sieve and collected in order to fill the pot. First, a layer of crushed stones was placed and matted with filter paper. Soil was added $(5 \mathrm{~cm}$ per layer) to achieve $35 \mathrm{~cm}$, making the soil bulk density $1.35 \mathrm{~g} / \mathrm{cm}^{3}$. The soil background values were as follows: total $\mathrm{N} 1.65 \mathrm{~g} / \mathrm{kg}$; total phosphorus $1.00 \mathrm{~g} / \mathrm{kg}$; total potassium $20.10 \mathrm{~g} / \mathrm{kg}$; effective ammonium nitrogen $47.25 \mathrm{mg} / \mathrm{kg}$; effective nitrate nitrogen $221.25 \mathrm{mg} / \mathrm{kg}$; effective phosphorus $99.92 \mathrm{mg} / \mathrm{kg}$; available potassium $184.75 \mathrm{mg} / \mathrm{kg}$; EC $220.85 \mathrm{mS} / \mathrm{m}$; pH 7.54.

\subsection{Corn planting and irrigation}

To complete pot filling, emitters were used to block the end with a plug, and the emitter was buried under the soil $(10 \mathrm{~cm}$ below the soil surface). To achieve one pot with three maize plants, three corn seeds were planted in one pot, leaving a strong corn plant at the seedling stage and removing the remaining two. Markov bottles were used for water supply, the bottles were placed on a tripod. The height was adjusted, maintaining a $2 \mathrm{~m}$ constant head to supply water for irrigation tape. Each branch was fitted with a valve control switch (Figure 1). The irrigation amount was read from a mark on the surface of the bottle.

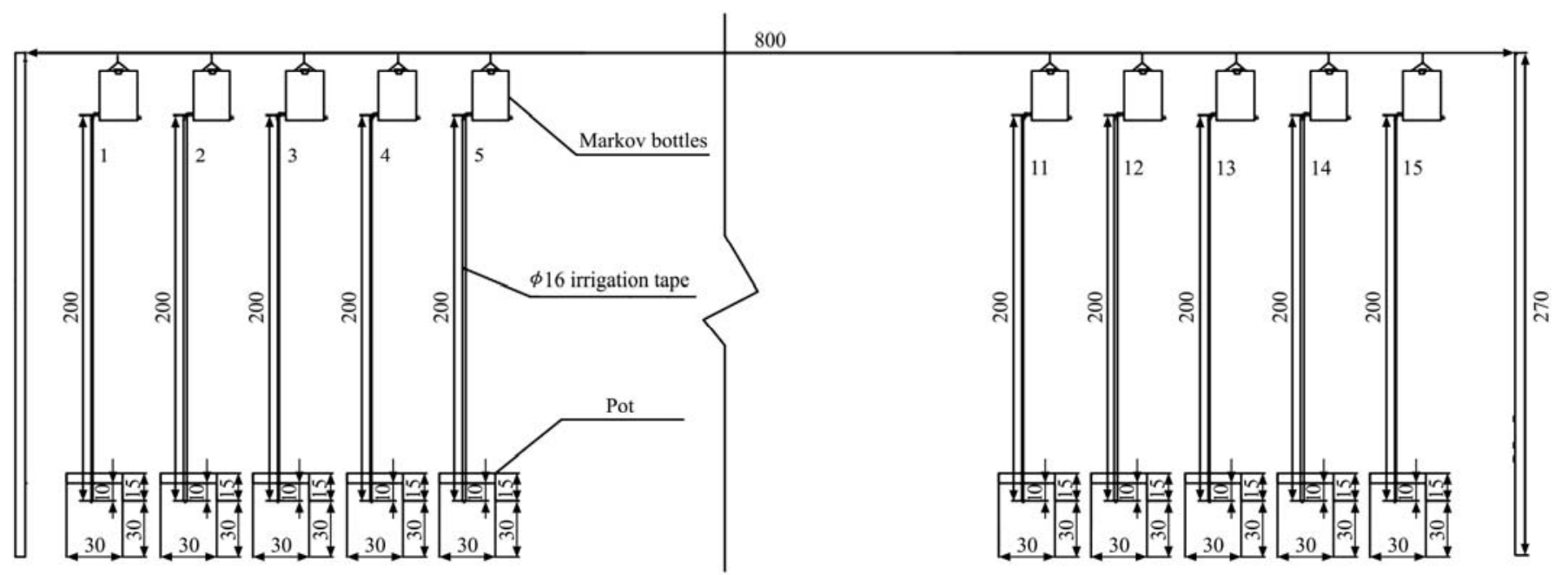

Figure 1 Sketch map of water supply system (unit: $\mathrm{cm}$ )

\subsection{Experimental design}

Before seeding, the water content was adjusted in order to reach the same soil water content in the pot. The soil was slowly irrigated in the pot, amount was approximately $2.1 \mathrm{~L}$ in a week (from July 12 th to July 20th) so that the soil moisture reached $80 \%$ of field capacity. The emitter flow of CK treatment was $1.4 \mathrm{~L} / \mathrm{h}$ at the $10 \mathrm{~m}$ water head and approximately $0.28 \mathrm{~L} / \mathrm{h}$ at the $2 \mathrm{~m}$ water head. Interval water was supplied. The flow rate of the remaining treatment was $0.01 \mathrm{~L} / \mathrm{h}$ at the $2 \mathrm{~m}$ water head, supplying continuous water to the soil pot. Markov bottles were filled every
$7 \mathrm{~d}$ or when Markov bottles were empty.

The conventional fertilization for base fertilizer application consisted of diammonium phosphate $\left(375 \mathrm{~kg} / \mathrm{hm}^{2}\right)$, potassium nitrate $\left(150 \mathrm{~kg} / \mathrm{hm}^{2}\right)$, and topdressing urea $\left(300 \mathrm{~kg} / \mathrm{hm}^{2}\right)$.

The total amount of base fertilizer was $6.8 \mathrm{~g} / \mathrm{pot}$, and the total amount of topdressing fertilizer was $4 \mathrm{~g} /$ pot. The NPK content of fertilizer used in the experiment was 14:16:15. The fertilization schedule is listed in Table 1.

Each treatment was repeated 15 times, with 60 pots in total. 
Table 1 Fertilization schedule

\begin{tabular}{|c|c|c|c|c|}
\hline & Base fertilizer & $\begin{array}{l}\text { Topdressing fertilizer in the } \\
\text { seedling stage }\end{array}$ & $\begin{array}{l}\text { Topdressing fertilizer in the } \\
\text { jointing stage }\end{array}$ & $\begin{array}{l}\text { Topdressing fertilizer in the tasseling stage } \\
\text { (Tasseling to flowering stage) }\end{array}$ \\
\hline A Treatment & No basal fertilizer & $33.3 \%$ of total fertilizer amount & $33.3 \%$ of total fertilizer amount & $33.3 \%$ of total fertilizer amount \\
\hline B Treatment & $\begin{array}{l}\text { Diammonium phosphate }\left(375 \mathrm{~kg} / \mathrm{hm}^{2}\right) \text {, } \\
\text { potassium nitrate }\left(150 \mathrm{~kg} / \mathrm{hm}^{2}\right)\end{array}$ & $0 \%$ of urea application & $50 \%$ of urea application & $50 \%$ of urea application \\
\hline D Treatment & No basal fertilizer & $20 \%$ of total fertilizer amount & $40 \%$ of total fertilizer amount & $40 \%$ of total fertilizer amount \\
\hline CK Treatment & $\begin{array}{l}\text { Diammonium phosphate }\left(375 \mathrm{~kg} / \mathrm{hm}^{2}\right) \text {, } \\
\text { potassium nitrate }\left(150 \mathrm{~kg} / \mathrm{hm}^{2}\right)\end{array}$ & $0 \%$ of urea application & $50 \%$ of urea application & $50 \%$ of urea application \\
\hline
\end{tabular}

\subsection{Soil water content, soil nitrogen and corn root system} measurements

\subsubsection{Sampling method}

Before breaking the pot, a soil drill (diameter $30 \mathrm{~mm}$ ) was used to get soil from the seven soil depths $(0-5 \mathrm{~cm}, 5-10 \mathrm{~cm}, 10-15 \mathrm{~cm}$, $15-20 \mathrm{~cm}, 20-25 \mathrm{~cm}, 25-30 \mathrm{~cm}$ and $30-35 \mathrm{~cm})$.

\subsubsection{Determination method}

The soil moisture content was determined by the drying method. After sampling, the soil was placed in an aluminum box and sealed. It was then placed in an oven at $105^{\circ} \mathrm{C}$ and dried to constant weight (through determination of sample weight before and after drying) for each layer of soil moisture before being converted to volumetric moisture content by bulk density.

$\theta_{w}=$ (aluminum box and soil quality before drying - aluminum box and soil sample quality after drying) / (aluminum box and soil sample quality after drying - empty aluminum box quality), $\theta_{v}=\theta_{w} \times \gamma$ where, $\theta_{v}$ is volumetric soil water content $(\% \mathrm{v} / \mathrm{v}) ; \theta_{w}$ is soil gravimetric water content $(\% \mathrm{w} / \mathrm{w}) ; \gamma$ is soil bulk density $\left(1.35 \mathrm{~g} / \mathrm{cm}^{3}\right)$

Soil nitrogen (nitrate nitrogen and ammonium nitrogen): The content of ammonium nitrogen and nitrate nitrogen in soil was determined by Auto Analyzer III. After sampling, extraction of $10 \mathrm{~g}$ of oven-dried soil with $100 \mathrm{~mL}$ of $1 \mathrm{~mol} / \mathrm{L} \mathrm{KCl}$ solution and then filtration with filter paper.

The dry matter of maize was determined by the drying method at the end of each growing stage, the plant was cut off from the ground, placed in the kraft bags, placed in the oven at $80^{\circ} \mathrm{C}$, and dried until the quality of the dry matter remained unchanged.

Corn root system: The roots were sampled by breaking pot and removed at every $5 \mathrm{~cm}$ depths of 0-5 cm, $5-10 \mathrm{~cm}, 10-15 \mathrm{~cm}, 15-$ $20 \mathrm{~cm}, 20-25 \mathrm{~cm}, 25-30 \mathrm{~cm}$ and $30-35 \mathrm{~cm}$, the soil column containing the roots was washed using a $0.4 \mathrm{~mm}$ sieve. The roots of the neighboring plants were not differentiated. After washing, root samples were stored at $-20^{\circ} \mathrm{C}$. The roots were floated in water in a transparent plastic tray $(20 \mathrm{~cm} \times 15 \mathrm{~cm})$ and scanned with a scanner (Epson1600, India). Larger root samples that could not fit into the tray were divided in order to avoid overlapping during scanning. Images were analyzed for total root length using WinRHIZO (version Pro 5.0, Canada).

\section{Experimental results}

\subsection{Variation trend of soil moisture content under different irrigation and fertilization treatments}

During the jointing stage, booting stage, tasseling stage, and grain filling stage, pots were broken in order to focus on the distribution of water and fertilizer within the soil.

Soil moisture trends of the jointing stage are shown in Figures 2(a)-(c), just under the drip irrigation tape. The soil moisture content in each treatment for the $5-10 \mathrm{~cm}$ depth showed a significant increasing trend. The soil moisture content in the CK treatment was higher compared to the other treatments, especially in the 25-35 cm depth. The soil moisture content of CK treatment showed a downward trend. During each depth of $5 \mathrm{~cm}$ in the horizontal direction of the drip irrigation tape, with the exception of CK treatment, there was no obvious downward movement of soil water. In the surface of $0-15 \mathrm{~cm}$ depth, $\mathrm{CK}$ treatment was higher than $\mathrm{B}$ treatment, but lower than $\mathrm{A}$ and $\mathrm{D}$ treatments. At the 15-35 cm depth, CK treatment was higher than the other treatments. During each depth of $10 \mathrm{~cm}$ in the horizontal direction of the drip irrigation tape, the soil moisture content of $\mathrm{CK}$ treatment was higher than that of A, B and D treatments in different layers.
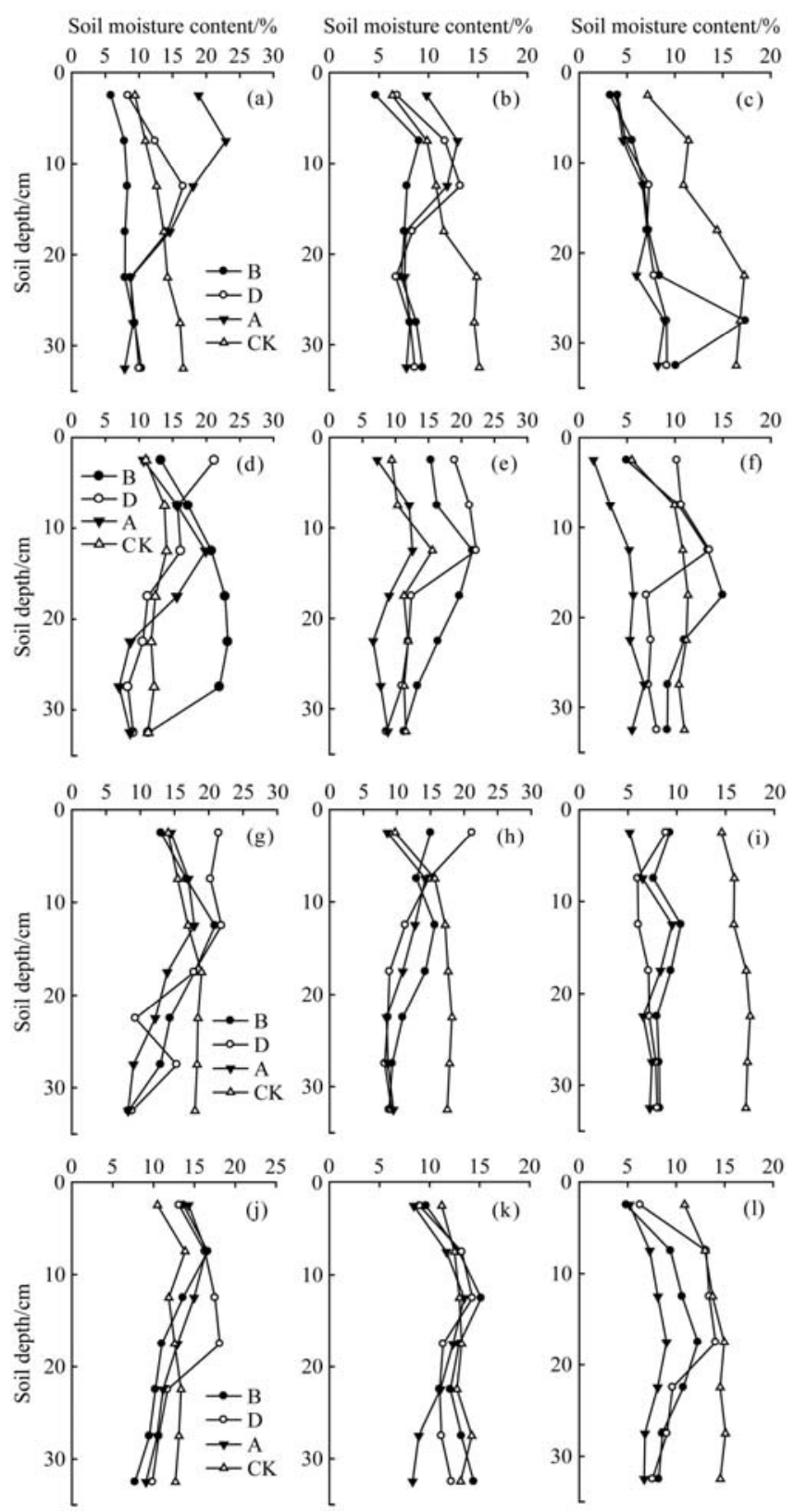

Figure 2 Soil moisture trends in the different stage measured from different positions

Soil moisture trends of the booting stage are shown in Figures 2(d)-(f), just under the drip irrigation tape. The soil moisture 
content of the B treatment showed a significant downward trend within the soil column and reached peak in the $20-30 \mathrm{~cm}$ depth of soil. Soil moisture of the A and D treatments on the surface was similar to the B treatment. As the depth increased, the water content decreased gradually, reaching the minimum at the 25$30 \mathrm{~cm}$ depth of soil. From the distance of $5 \mathrm{~cm}$ in the horizontal direction of the drip irrigation tape, the soil moisture content of all treatments was highest near the emitter. Furthermore, the peak value was found at the $10-15 \mathrm{~cm}$ soil depth, and the water contents were close to among the treatments. The A treatment water had less lateral and vertical movement, while the D treatment water had large lateral migration. From the distance of $10 \mathrm{~cm}$ in the horizontal direction of the drip irrigation tape, the moisture content of the A treatment was lower than that of other treatments, and the peak value of other treatments was in the $10-20 \mathrm{~cm}$ depth soil layer.

Table 2 Soil moisture content just below the emitter

\begin{tabular}{ccccc}
\hline $\begin{array}{c}\text { Soil moisture } \\
\text { /\% }\end{array}$ & $\begin{array}{c}\text { Jointing } \\
\text { stage }\end{array}$ & $\begin{array}{c}\text { Booting } \\
\text { stage }\end{array}$ & $\begin{array}{c}\text { Tasseling } \\
\text { stage }\end{array}$ & $\begin{array}{c}\text { Grain filling } \\
\text { stage }\end{array}$ \\
\hline B & 8.07 & 19.04 & 18.82 & 15.12 \\
D & 14.48 & 15.97 & 21.05 & 16.91 \\
A & 20.49 & 17.79 & 17.45 & 15.7 \\
CK & 11.79 & 13.94 & 16.21 & 12.86 \\
\hline
\end{tabular}

Soil moisture trends of the tasseling stage are shown in Figures 2(g)-(i) just under the drip irrigation tape. The soil moisture content of the $0-15 \mathrm{~cm}$ soil depth was similar in each treatment. However, in the $15 \mathrm{~cm}$ depth, the moisture content of each treatment varied, and the $\mathrm{CK}$ treatment showed that water moved to the deep layer. From the distance of $5 \mathrm{~cm}$ in the horizontal direction of the drip irrigation tape, the water content in the CK treatment was lower on the surface and higher in the deep soil layer compared to other treatments. The peak value of the B treatment occurred at the depth of $0-5 \mathrm{~cm}$, and the soil moisture content decreased gradually as the depth increased. From the distance of $10 \mathrm{~cm}$ in the horizontal direction of the drip irrigation tape, the difference between the soil moisture content of each treatment was larger, and the CK treatment had the highest moisture content, but there was no difference between the surface and subsurface water content.

Soil moisture trends in the grain filling stage are shown in Figures 2(j)-(l), just under the drip irrigation tape. The soil moisture content of each treatment was similar, with the peak value located at the $5-10 \mathrm{~cm}$ depth. At the $0-15 \mathrm{~cm}$ depth, the water content of the CK treatment was lower than the other treatments. Furthermore, the water content at the $15-35 \mathrm{~cm}$ depth was higher than the other treatments. From the distance of $5 \mathrm{~cm}$ in the horizontal direction of the drip irrigation tape, all treatments were maintained at the same basic level, and the deep percolation of the A treatment in the $25-35 \mathrm{~cm}$ depth was lower than that of other treatments. The D treatment was similar to the A treatment. From the distance of $10 \mathrm{~cm}$ in the horizontal direction of the drip irrigation tape, the CK treatment had the highest moisture content; the peak value was located at the $25-30 \mathrm{~cm}$ depth. The A treatment had the lowest moisture content in each soil layer, with the peak value occurring at the depth of $15-20 \mathrm{~cm}$

The four treatments, with the exception of the A treatment, showed an initial increase in the soil moisture content just below the emitter, followed by a decrease. The soil moisture content of the A treatment tended to decrease gradually. The soil moisture content just below the emitter in the CK treatment was maintained at a low level, while the soil moisture content just below the emitter in the continuous irrigation of each treatment was maintained at a relatively high level, especially at the booting stage and tasseling stage. In the early grain filling stage, the soil moisture content decreased, indicating that small flow irrigation is not sufficient to meet the needs of maize.

\subsection{Changes of soil ammonium nitrogen $\left(\mathrm{NH}_{4}^{+}\right)$in different growth stages}

Soil ammonium nitrogen changes in the jointing stage are shown in Figures 3(a)-(c). The A and D treatments increased fluctuations below the $20 \mathrm{~cm}$ soil depth just under the drip irrigation tape. From the distance of $5 \mathrm{~cm}$ in the horizontal soil ammonium nitrogen reduced and then increased at the depth of $5-10 \mathrm{~cm}$. The peak value appeared at the $35 \mathrm{~cm}$ depth. Just under the drip irrigation tape, the peak value appeared at the depth of $10-15 \mathrm{~cm}$ from the distance of $5 \mathrm{~cm}$ in the horizontal direction of the drip irrigation tape. From the distance of $10 \mathrm{~cm}$ in the horizontal direction of the drip irrigation tape, the peak value appeared at the depth of $20-25 \mathrm{~cm}$ direction of drip irrigation tape, the ammonium nitrogen increased with increasing depth.

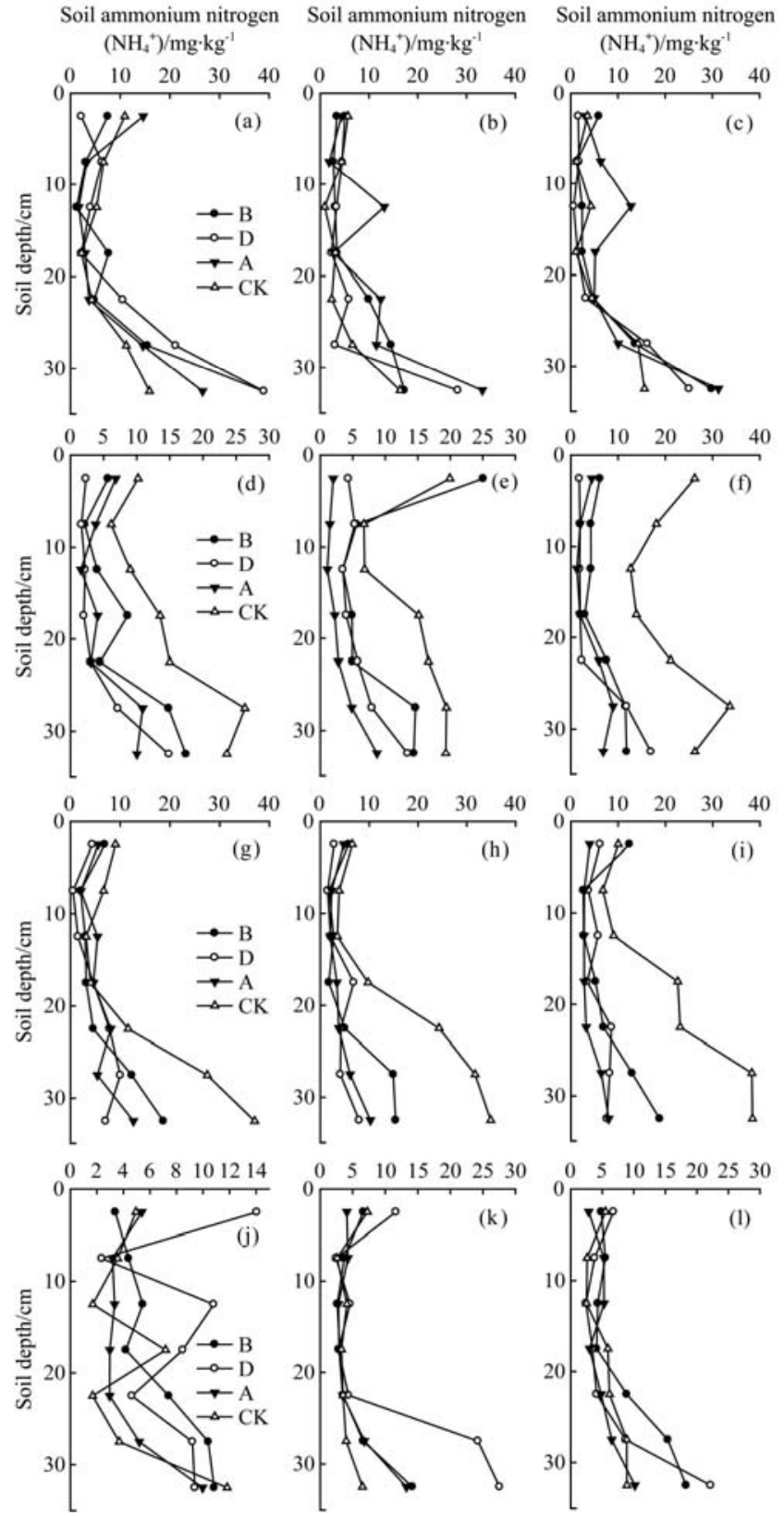

Figure 3 Soil ammonium nitrogen trends in the different stage measured from different positions 
Soil ammonium nitrogen changes in the booting stage are shown in Figures 3(d)-(f), just under the drip irrigation tape. The ammonium nitrogen levels in each treatment increased with an increase in soil depth. With the exception of the $\mathrm{B}$ and $\mathrm{D}$ treatments, which reached the peak value at the $30-35 \mathrm{~cm}$ depth, the peak values of the other treatment were observed at the 25 $30 \mathrm{~cm}$ depth. From the distance of $5 \mathrm{~cm}$ in the horizontal direction of the drip irrigation tape, the $\mathrm{NH} 4-\mathrm{N}$ in soil from the $\mathrm{B}$ and $\mathrm{CK}$ treatments decreased first and then increased, and the peak value was located at the $0-5 \mathrm{~cm}$ depth. The A and D treatments showed that soil ammonium nitrogen increased slowly with an increase in soil depth, and the ammonium nitrogen level in the soil was lower than the other treatments. From the distance of $10 \mathrm{~cm}$ in the horizontal direction of the drip irrigation tape, soil ammonium nitrogen levels of the B treatment remained in a low range (approximately $5-10 \mathrm{mg} / \mathrm{kg}$ ). The CK treatment increased first and then decreased, and the peak value was observed at the $25-30 \mathrm{~cm}$ depth.

Soil ammonium nitrogen changes in the tasseling stage are shown in Figures 3(g)-(i). As the soil depth increased, the ammonium nitrogen levels decreased first and then increased, and the fluctuation point appeared at the depth of $5-15 \mathrm{~cm}$. From the distance of $0 \mathrm{~cm}, 5 \mathrm{~cm}$ and $10 \mathrm{~cm}$ in the horizontal direction of the drip irrigation tape, the soil ammonium nitrogen values of the $\mathrm{B}$ treatment were lower than the CK treatment, and its peak value was located at the $30-35 \mathrm{~cm}$ depth. CK treatment in the $0-15 \mathrm{~cm}$ soil depth was closer, but slightly larger compared with the rest of the treatments. In the soil depth of $15-35 \mathrm{~cm}$, the value of soil ammonium nitrogen in the CK treatment was significantly larger compared to the other treatments.

Soil ammonium nitrogen changes in the grain filling stage are shown in Figures 3(j)-(1), from the distance of $0 \mathrm{~cm}, 5 \mathrm{~cm}$ and $10 \mathrm{~cm}$ in the horizontal direction of the drip irrigation tape. Ammonium nitrogen levels were similar. Just under the drip irrigation tape, the ammonium nitrogen levels of each treatment fluctuated greatly. The $\mathrm{D}$ treatment showed the maximum fluctuation. From the distance of $5 \mathrm{~cm}$ and $10 \mathrm{~cm}$ in the horizontal direction of the drip irrigation tape, the ammonium nitrogen levels of each treatment were maintained at a low level of $0-20 \mathrm{mg} / \mathrm{kg}$. From the distance of $5 \mathrm{~cm}$ in the horizontal direction of the drip irrigation tape, the $\mathrm{D}$ treatment showed a sudden increase in the 25-35 cm soil layer depth.

Table 3 Soil ammonium nitrogen just below the emitter

\begin{tabular}{ccccc}
\hline $\begin{array}{c}\text { Soil ammonium } \\
\text { nitrogen } / \mathrm{mg}^{-1} \mathrm{~kg}^{-1}\end{array}$ & $\begin{array}{c}\text { Jointing } \\
\text { stage }\end{array}$ & $\begin{array}{c}\text { Booting } \\
\text { stage }\end{array}$ & $\begin{array}{c}\text { Tasseling } \\
\text { stage }\end{array}$ & $\begin{array}{c}\text { Grain filling } \\
\text { stage }\end{array}$ \\
\hline B & 2.14 & 3.09 & 2.50 & 4.92 \\
D & 5.15 & 1.94 & 1.00 & 6.58 \\
A & 2.46 & 2.69 & 3.76 & 3.25 \\
CK & 5.96 & 7.58 & 4.88 & 2.62 \\
\hline
\end{tabular}

Continuous water treatments in B, D and A treatments delayed the peak value of ammonium nitrogen, appearing in the early stage of grain filling. The B and D treatments appeared in the early filling stage. The A treatment appeared in the tasseling stage, while the CK treatment showed a peak of ammonium nitrogen in the jointing stage. Slow continuous water supply reduced the peak value of ammonium nitrogen near the emitter to a certain extent. The peak value of CK treatment was $7.58 \mathrm{mg} / \mathrm{kg}$, while the $\mathrm{B}, \mathrm{D}$ and A treatments were $4.92 \mathrm{mg} / \mathrm{kg}, 6.58 \mathrm{mg} / \mathrm{kg}$ and $3.76 \mathrm{mg} / \mathrm{kg}$, respectively.

\subsection{Changes of soil nitrate nitrogen $\left(\mathrm{NO}_{3}{ }^{-}\right)$in different growth stages}

Soil nitrate nitrogen changes in the jointing stage are shown in Figures 4(a)-(c). In the $20-35 \mathrm{~cm}$ soil depth, each treatment from different distances in the horizontal direction of the drip irrigation tape increased with increases in soil depth, showing a trend of rising fluctuations. The peak appeared at the $35 \mathrm{~cm}$ soil depth. In the $0-20 \mathrm{~cm}$ depth, the soil nitrate nitrogen was similar and had little fluctuation.

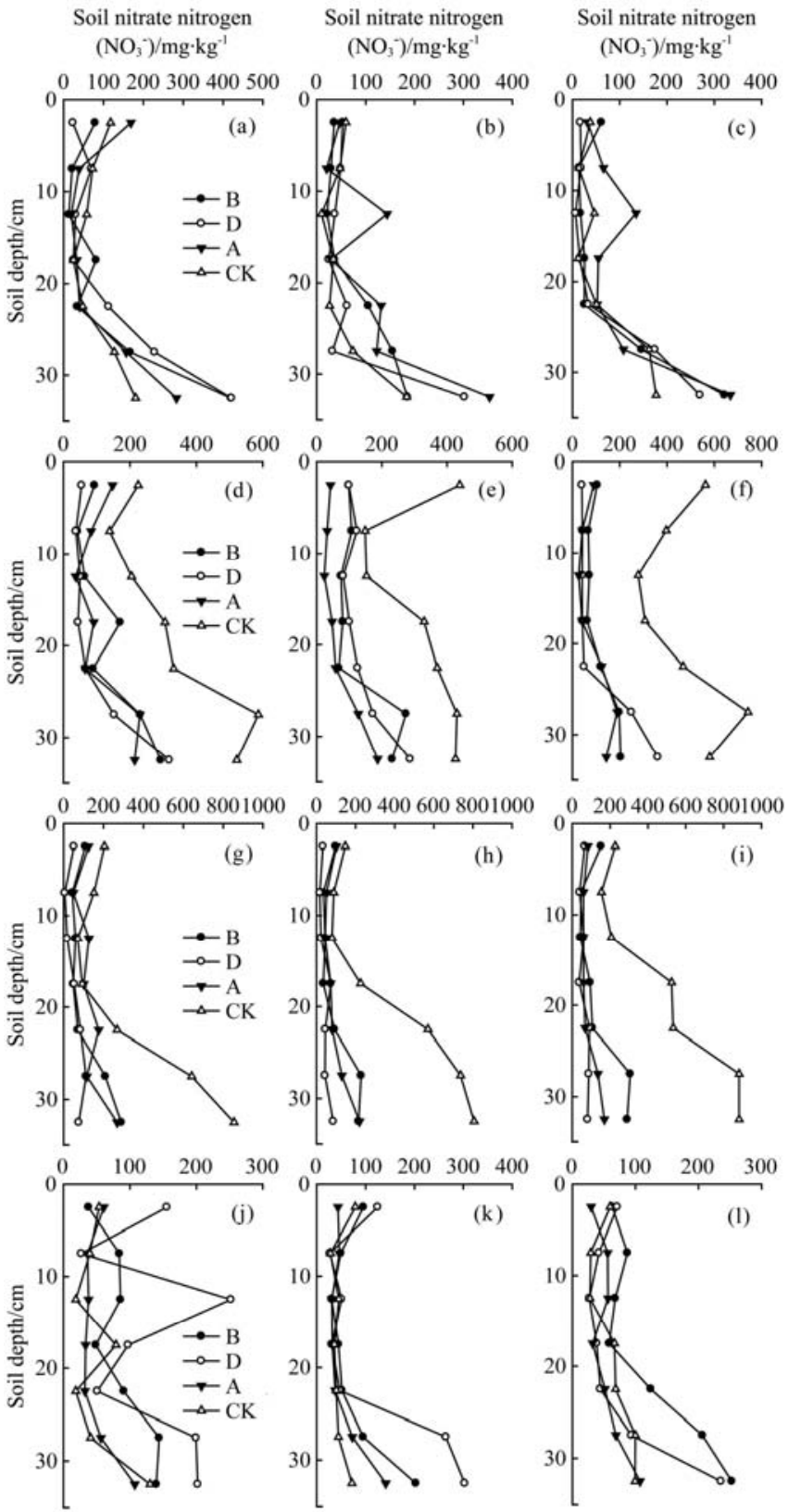

Figure 4 Soil nitrate nitrogen trends in different stages measured from different positions

Soil nitrate nitrogen changes in the booting stage are shown in Figures 4(d)-(f), just under the drip irrigation tape. Soil nitrate nitrogen levels at the $0-5 \mathrm{~cm}$ depth did not show a difference. In the $5-35 \mathrm{~cm}$ soil depth, each treatment showed a fluctuation trend, and the peak value was located at the $25-35 \mathrm{~cm}$ depth. At a distance of $5 \mathrm{~cm}$ from the horizontal direction of the drip irrigation, the treatments were at a lower value at the depth of $5-10 \mathrm{~cm}$. From the distance of $5 \mathrm{~cm}$ in the horizontal direction of the drip irrigation tape, the soil nitrate nitrogen in the $\mathrm{CK}$ treatment was higher than other treatments. The soil nitrate nitrogen levels 
initially decreased, then increased, and then decreased again. The peak value was located at the $30-35 \mathrm{~cm}$ depth.

Figures 4(g)-(i) show the soil nitrate nitrogen changes in the tasseling stage from the distance of $0 \mathrm{~cm}, 5 \mathrm{~cm}$ and $10 \mathrm{~cm}$ in the horizontal direction of the drip irrigation tape. The content of nitrate nitrogen in each soil layer was higher in the CK treatment compared to the $\mathrm{B}$ treatment. The peak value was located at the $30-35 \mathrm{~cm}$ soil depth. In the $0-15 \mathrm{~cm}$ depth of soil, the fluctuation of each treatment was slower. Under the $15 \mathrm{~cm}$ soil layer, each treatment showed a larger fluctuation trend. The CK treatment was a short time leaching, but the larger flow of dripper discharge significantly increased the leaching of nitrate nitrogen. The remaining treatments were maintained at a lower level.

Soil nitrate nitrogen changes in the grain filling stage are shown in Figures 4(j)-(1), just under the drip irrigation tape. The soil nitrate nitrogen levels of the B treatment first increased, then decreased, and then increased with an increase in soil depth. The CK treatment showed the opposite trend, and the peak value was located at the soil depth of 30-35 cm. At a distance of $5 \mathrm{~cm}$ from the horizontal direction of the drip irrigation tape, the soil nitrate nitrogen levels were kept at a low level at the $0-25 \mathrm{~cm}$ soil depth before increasing rapidly at the depth of $25-35 \mathrm{~cm}$. The peak value was located at the depth of $30-35 \mathrm{~cm}$. From the distance of $10 \mathrm{~cm}$ in the horizontal direction of the drip irrigation tape, soil nitrate nitrogen levels of the $\mathrm{B}$ treatment were higher than CK treatment in the $0-35 \mathrm{~cm}$ soil depth, and the peak value was located at the $30-35 \mathrm{~cm}$ depth.

Table 4 Soil nitrate nitrogen just below the emitter

\begin{tabular}{ccccc}
\hline $\begin{array}{c}\text { Soil nitrate } \\
\text { nitrogen } / \mathrm{mg}^{-} \mathrm{kg}^{-1}\end{array}$ & $\begin{array}{c}\text { Jointing } \\
\text { stage }\end{array}$ & $\begin{array}{c}\text { Booting } \\
\text { stage }\end{array}$ & $\begin{array}{c}\text { Tasseling } \\
\text { stage }\end{array}$ & $\begin{array}{c}\text { Grain filling } \\
\text { stage }\end{array}$ \\
\hline B & 17.23 & 52.91 & 51.30 & 84.96 \\
D & 49.63 & 43.54 & 11.76 & 139.40 \\
A & 28.88 & 59.87 & 87.49 & 36.92 \\
CK & 65.26 & 171.72 & 111.22 & 29.05 \\
\hline
\end{tabular}

Continuous water treatments in $\mathrm{B}, \mathrm{D}$ and $\mathrm{A}$ treatments delayed the peak value of soil nitrate nitrogen. The B and D treatments appeared in the early filling stage. The A treatment appeared in the tasseling stage, while the nitrate nitrogen peak of the CK treatment appeared in the jointing stage. Slow continuous water supply reduced the peak value of nitrate nitrogen near the emitter to a certain extent. The peak value of the $\mathrm{CK}$ treatment was $171.72 \mathrm{mg} / \mathrm{kg}$, while the peak values of the B, D and A treatments were $84.96 \mathrm{mg} / \mathrm{kg}, 139.40 \mathrm{mg} / \mathrm{kg}$ and $87.49 \mathrm{mg} / \mathrm{kg}$, respectively.

\subsection{Total amount of soil nitrogen in the pot during different} growth stages

The contents of soil ammonium nitrogen and soil nitrate nitrogen in the pot are shown in Figure 5 and Figure 6 . The trends of soil ammonium and nitrate nitrogen were similar.

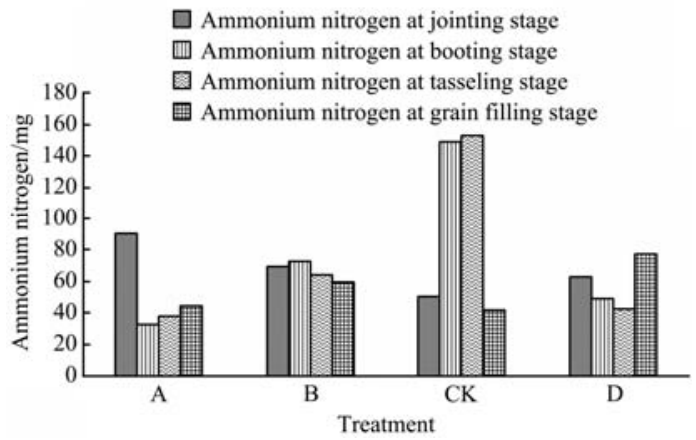

Figure 5 Content of soil ammonium nitrogen in the pot during the growing season

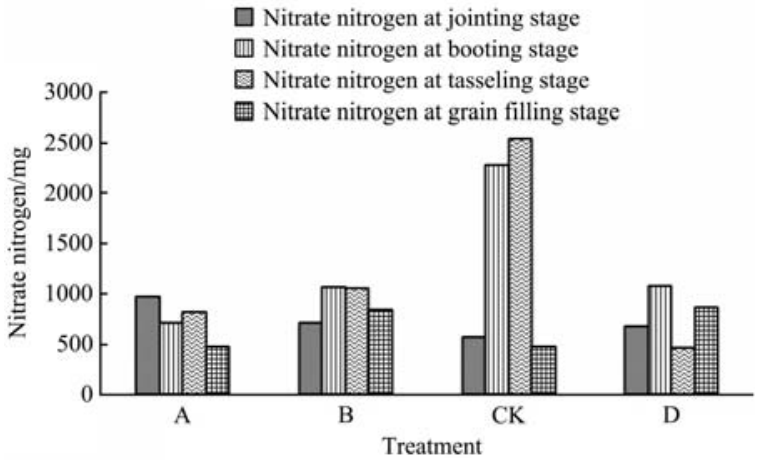

Figure 6 Content of soil nitrate nitrogen in the pot during the growing season

Table $5 \mathrm{NH}_{4}{ }^{+}-\mathrm{N}$ in the pot during the growing season

\begin{tabular}{lcccc}
\hline \multicolumn{1}{c}{ Treatment/mg } & A & B & CK & D \\
\hline Soil $\mathrm{NH}_{4}{ }^{+}$-N at jointing stage & 90.74 & 69.46 & 50.8 & 63.24 \\
Soil $\mathrm{NH}_{4}{ }^{+}$-N at booting stage & 33.08 & 73.02 & 149.34 & 49.04 \\
Soil $\mathrm{NH}_{4}{ }^{+}-\mathrm{N}$ at tasseling stage & 38.25 & 64.2 & 153.35 & 42.98 \\
Soil $\mathrm{NH}_{4}{ }^{+}-\mathrm{N}$ at grain filling stage & 44.58 & 59.5 & 42.25 & 77.38 \\
\hline
\end{tabular}

Table $6 \mathrm{NO}_{3}{ }^{-} \mathrm{N}$ in the pot during the growing season

\begin{tabular}{lcccc}
\hline \multicolumn{1}{c}{ Treatment/mg } & $\mathrm{A}$ & $\mathrm{B}$ & $\mathrm{CK}$ & $\mathrm{D}$ \\
\hline Soil $\mathrm{NO}_{3}{ }^{-}-\mathrm{N}$ at jointing stage & 968.53 & 715.7 & 565.8 & 677.00 \\
Soil $\mathrm{NO}_{3}{ }^{-}-\mathrm{N}$ at booting stage & 712.67 & 1059.59 & 2283.35 & 1073.67 \\
Soil $\mathrm{NO}_{3}{ }^{-}-\mathrm{N}$ at tasseling stage & 817.13 & 1051.53 & 2540.56 & 461.54 \\
Soil $\mathrm{NO}_{3}{ }^{-}-\mathrm{N}$ at grain filling stage & 478.24 & 836.64 & 469.48 & 862.97 \\
\hline
\end{tabular}

In the jointing stage, the soil $\mathrm{NH}_{4}^{+}-\mathrm{N}$ was the highest $(90.74 \mathrm{mg})$ in the A treatment. The content of soil nitrate nitrogen and ammonium nitrogen under different treatments showed a large difference. The ammonium nitrogen and nitrate nitrogen levels in the CK treatment were about half of the A treatment.

In the booting stage, the content of soil $\mathrm{NH}_{4}{ }^{+} \mathrm{N}$ and soil $\mathrm{NO}_{3}{ }^{-}-\mathrm{N}$ was highest in the $\mathrm{CK}$ treatment, with levels of $149.34 \mathrm{mg}$ and $2283.35 \mathrm{mg}$, respectively. The B treatment had the second highest content of ammonium nitrogen $(73.02 \mathrm{mg})$, followed by the D treatment $(49.04 \mathrm{mg})$ and the A treatment $(33.08 \mathrm{mg})$. Soil nitrate nitrogen was slightly different. The CK treatment had the highest levels of soil nitrate nitrogen. There was no difference between the B and D treatments (approximately $1200 \mathrm{mg}$ ), and the A treatment showed lowest levels of $712.67 \mathrm{mg}$.

In the tasseling stage, The CK treatment had the highest levels of soil ammonium nitrogen and nitrate nitrogen with the values of $149.34 \mathrm{mg}$ and $2540.56 \mathrm{mg}$, respectively. The B treatment showed nitrogen levels of $64.2 \mathrm{mg}$ and $1051.53 \mathrm{mg}$ for soil ammonium nitrogen and nitrate nitrogen, respectively. The ammonium nitrogen levels of the $\mathrm{D}$ treatment were lower than the B treatment $(42.98 \mathrm{mg})$. The nitrate nitrogen levels of the D treatment were the lowest $(461.54 \mathrm{mg})$, and both kinds of nitrogen content were lowest in the A treatment.

In the grain filling stage, the content of soil ammonium nitrogen and nitrate nitrogen were highest in the $\mathrm{D}$ treatment (77.38 $\mathrm{mg}$ and $862.97 \mathrm{mg}$, respectively), followed by the B treatment $(59.5 \mathrm{mg}$ and $836.64 \mathrm{mg}$, respectively), the A treatment (44.58 $\mathrm{mg}$ and $478.24 \mathrm{mg}$, respectively) and the CK treatment (42.25 $\mathrm{mg}$ and $469.48 \mathrm{mg}$, respectively). In summary, the soil nitrate nitrogen and ammonium nitrogen levels of each treatment showed a large difference.

\subsection{The nitrogen use efficiency}

The crop nitrogen use efficiency was calculated by the corn 
dry weight in the pot (Table 7). The B and CK treatments did not use fertilizer in the seedling stage, and thus the nitrogen utilization efficiency in the seedling stage cannot be calculated. August $2^{\text {nd }}$, September $10^{\text {th }}$, September $18^{\text {th }}$ and October $8^{\text {th }}$ represent four time sections at the end of the corn seedling stage, jointing stage, booting stage and tasseling stage, respectively. Among these times, the nitrogen utilization rate of the A treatment was highest in each growth period, except for the seedling stage. The nitrogen utilization rate of the $\mathrm{D}$ treatment was highest in the seedling stage. The D treatment in the later of the three growth stages has smaller utilization rate than that of the A treatment, which was greater than that of the other treatments.

Table 7 Nitrogen use efficiency in the pot

\begin{tabular}{ccccc}
\hline Treatment & Aug. $2^{\text {nd }}$ & Sep. $10^{\text {th }}$ & Sep. $18^{\text {th }}$ & Oct. $8^{\text {th }}$ \\
\hline A & 24.88 & 272.46 & 495.30 & 887.61 \\
B & NA & 63.31 & 105.47 & 235.45 \\
CK & NA & 70.89 & 99.13 & 326.66 \\
D & 27.42 & 188.95 & 263.71 & 757.12 \\
\hline
\end{tabular}

Note: Nitrogen use efficiency were calculated by the amount of dry matter/ nitrogen content of fertilizer applied in each growth stage, there were no unit, NA represents no data because the $\mathrm{B}$ and CK were $0 \%$ of urea application.

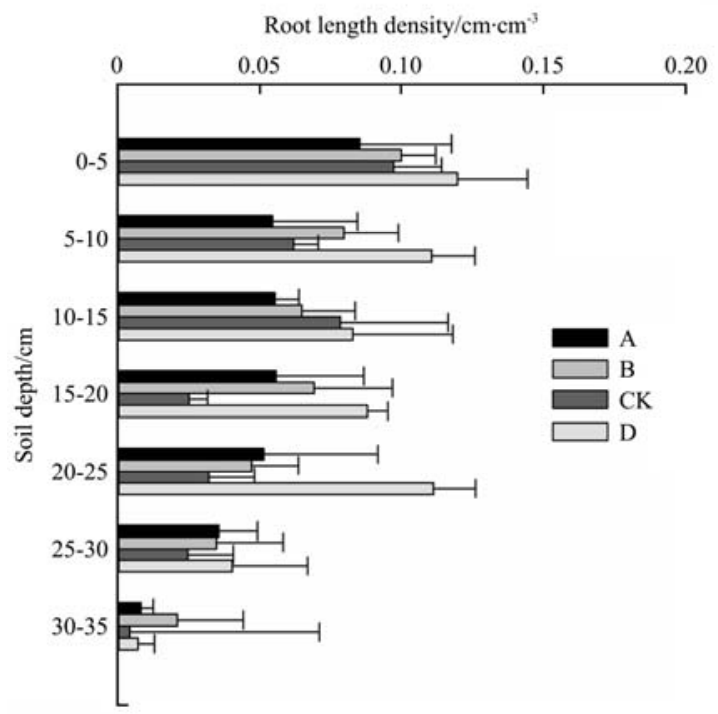

Figure 7 Root length density and root surface area at the seedling stages
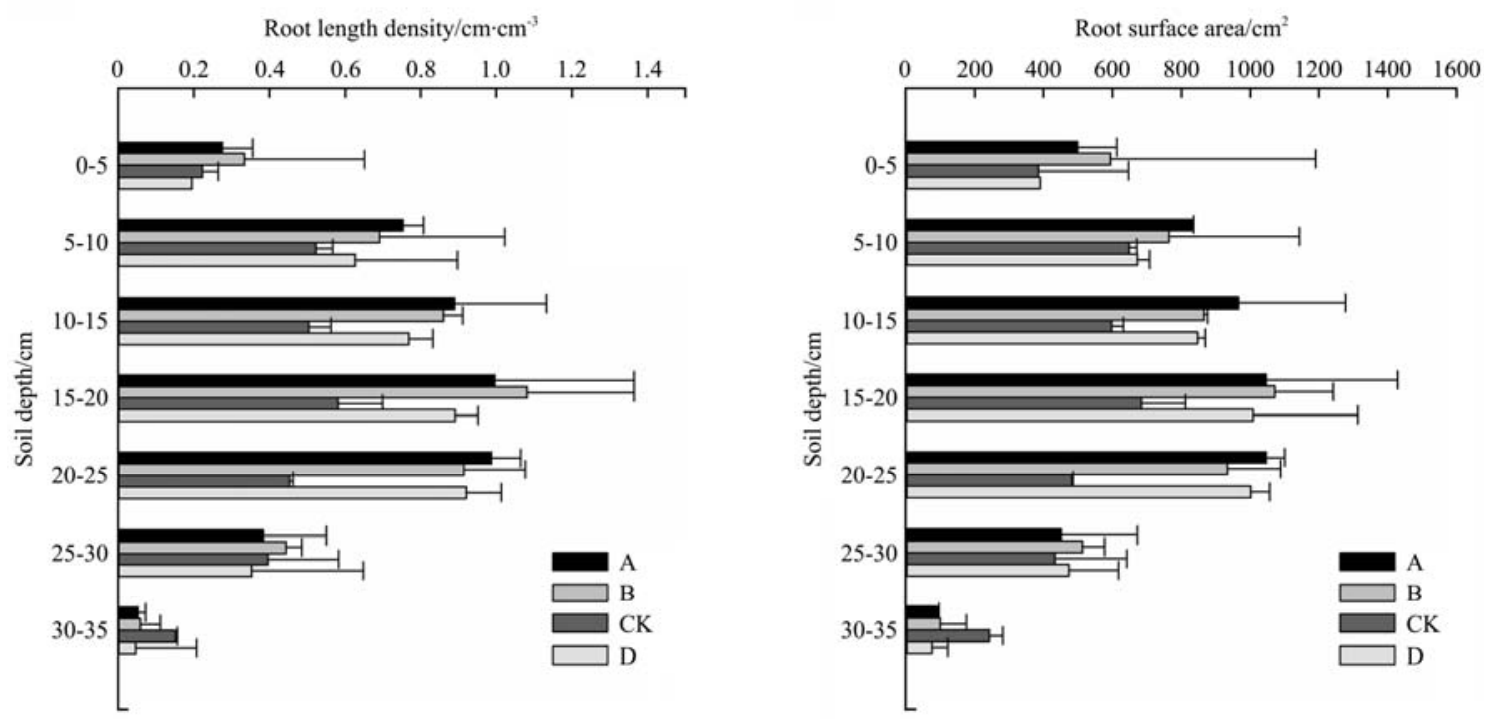

Figure 8 Root length density and root surface area at the jointing stage
The root length density and surface area at the seedling stage fluctuates and decreases with an increase in soil depth (Figure 7). The root length density and surface area of the D treatment was the largest, peaking at the $20-25 \mathrm{~cm}$ soil depth. The D treatment had a trend toward significantly increased deep roots compared to the other treatments, especially at the $15-30 \mathrm{~cm}$ depth. The root surface area decreased with an increase in depth, and the peak value occurred at the depth of $0-5 \mathrm{~cm}$. The $\mathrm{B}$ treatment was greatest in the surface layer $(0-5 \mathrm{~cm})$ and deep layer $(30-35 \mathrm{~cm})$.

The root length density and root surface area of the four treatments first increased and then decreased with an increase in soil depth at the jointing stage (Figure 8). At the surface depth of $0-5 \mathrm{~cm}$, the B treatment had the longest root length, followed by the A treatment and the D treatment. At the $15-20 \mathrm{~cm}$ depth, the $\mathrm{B}$ treatment was the highest, and the $\mathrm{CK}$ treatment was the lowest.

The CK treatment showed a trend of lower surface and higher bottom at the root length density (Figure 9). The root length density increased at the $20-35 \mathrm{~cm}$ depth, but the root length densities of the other treatments showed a uniform trend in the depth of each soil layer. At the root surface area, the D treatment was higher in the surface layer compared to the other treatments, especially at the $0-5 \mathrm{~cm}$ depth, while the $\mathrm{CK}$ treatment increased suddenly at the $20-35 \mathrm{~cm}$ depth.

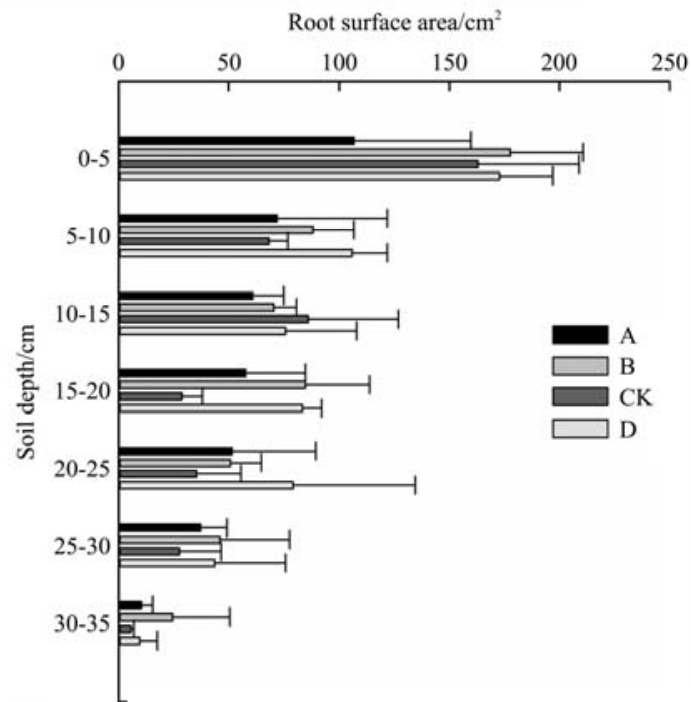



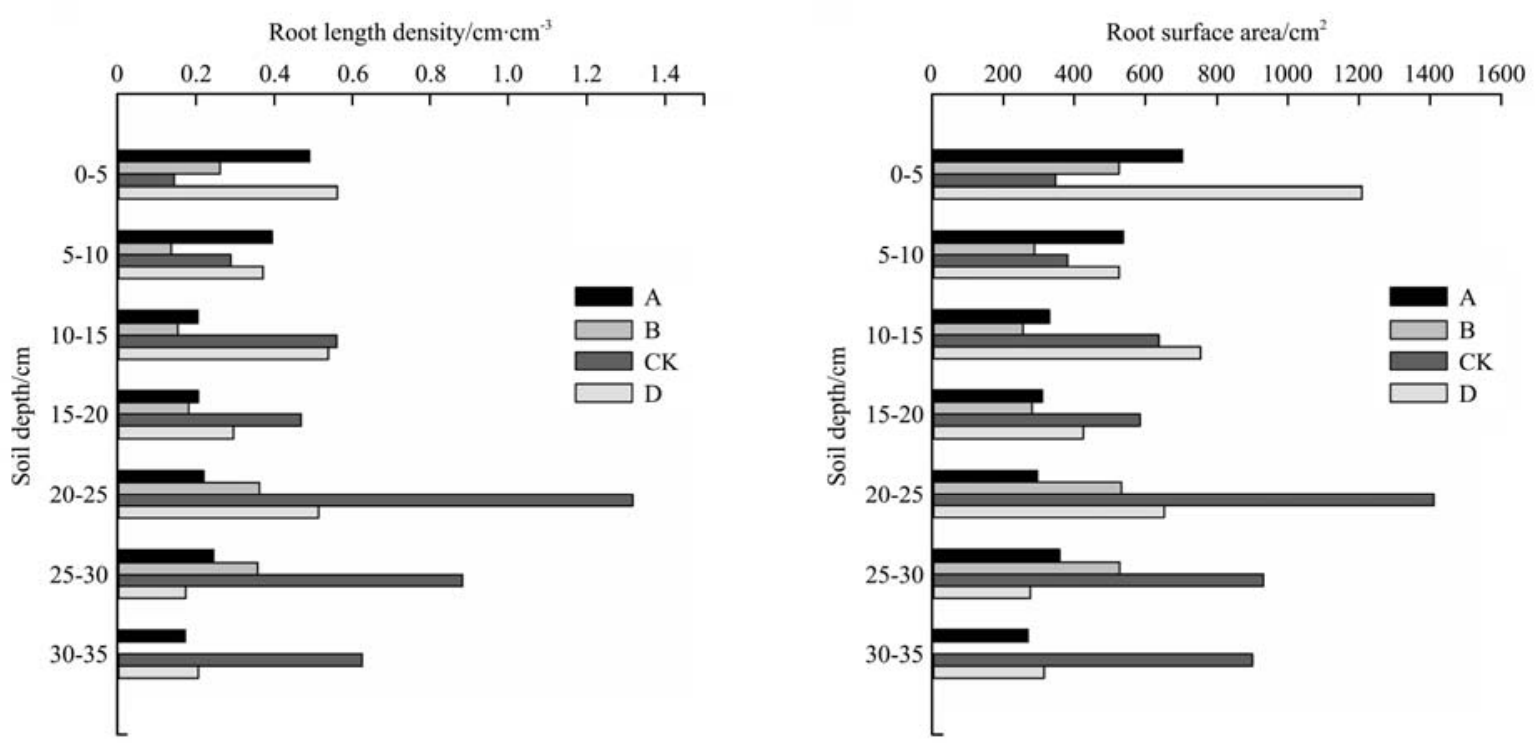

Figure 9 Root length density and root surface area at the tasseling stage

The D treatment at the booting stage showed a trend of fluctuations in root length density (Figure 10). The CK treatment was similar to the D treatment, and root length density in each depth was maintained at a high level. The A treatment showed a decreasing trend after the first increase, peaking at the $20-25 \mathrm{~cm}$ soil depth. The B treatment showed a decreasing-increasing trend, and the root length density was the lowest at the $10-15 \mathrm{~cm}$ depth. At the root surface area, each treatment showed a fluctuation trend. The peak value of the $\mathrm{B}$ treatment occurred at the $0-5 \mathrm{~cm}$ depth, and the peak value of the CK treatment occurred at the $20-25 \mathrm{~cm}$ depth. The peak value of the A treatment occurred at the 20$25 \mathrm{~cm}$ depth, and the peak value of the $\mathrm{D}$ treatment occurred at the $0-5 \mathrm{~cm}$ depth.

In terms of maturity stage (Figure 11), the A treatment was higher at the surface $0-10 \mathrm{~cm}$ depth than other treatments in root length density, and the $\mathrm{D}$ treatment was higher than other treatments at the $15-30 \mathrm{~cm}$ depth. Within the $30-35 \mathrm{~cm}$ depth, the CK treatment root length density was higher than the other treatments. In terms of the root surface area, the A treatment has higher value than other treatments in the $0-15 \mathrm{~cm}$ depth. The D

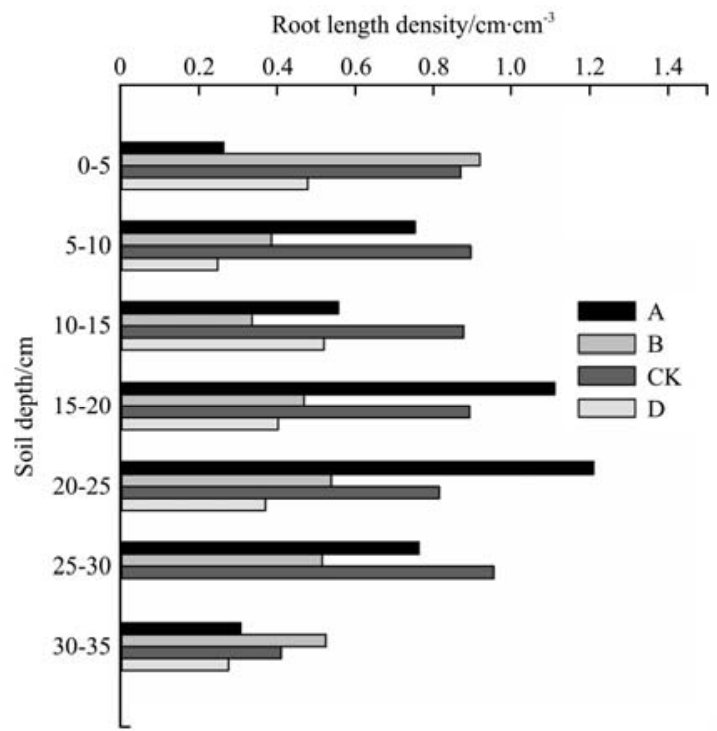

treatment has the highest value in the $25-30 \mathrm{~cm}$ depth, and the CK treatment has the highest value at the $10-25 \mathrm{~cm}$ and $30-35 \mathrm{~cm}$ depths. Therefore, the $\mathrm{D}$ and $\mathrm{CK}$ treatments have increased root surface area by the depth, with larger root surface areas occurring in the deep soil layer.

The dry matter accumulation in the jointing stage was between 10-30 g (Figure 12). The CK treatment has the highest value, with approximately $30.5 \mathrm{~g}$ accumulation, which was comparable to the $\mathrm{B}$ treatment. The $\mathrm{A}$ and $\mathrm{D}$ treatments approached approximately $20 \mathrm{~g}$. The maximum amount of dry matter accumulation in the tasseling stage occurred in the $\mathrm{B}$ treatment (approximately $45.46 \mathrm{~g}$ ), which was similar to that of $\mathrm{CK}$ treatment. In the early grain filling stage, the maximum amount of dry matter accumulation was in the CK treatment (approximately $140.8 \mathrm{~g}$ ), and the A treatment was the lowest (about half of CK treatment). Therefore, B treatment (continuous irrigation) can increase the dry matter accumulation of maize in the tasseling stage, and CK treatment (pulse irrigation) has an increasing effect on dry matter accumulation in maize in the jointing and maturity stages.

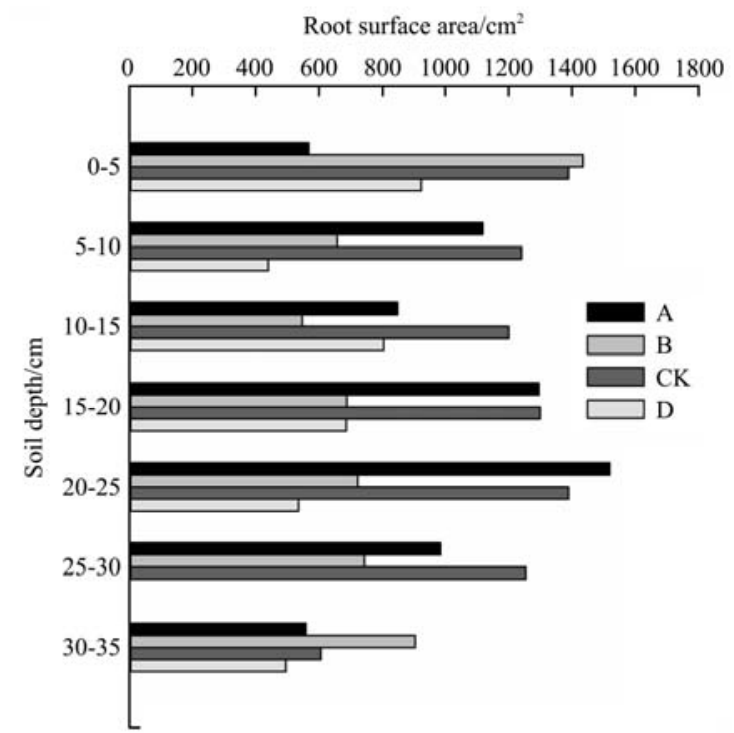

Figure 10 Root length density and root surface area at the booting stage 

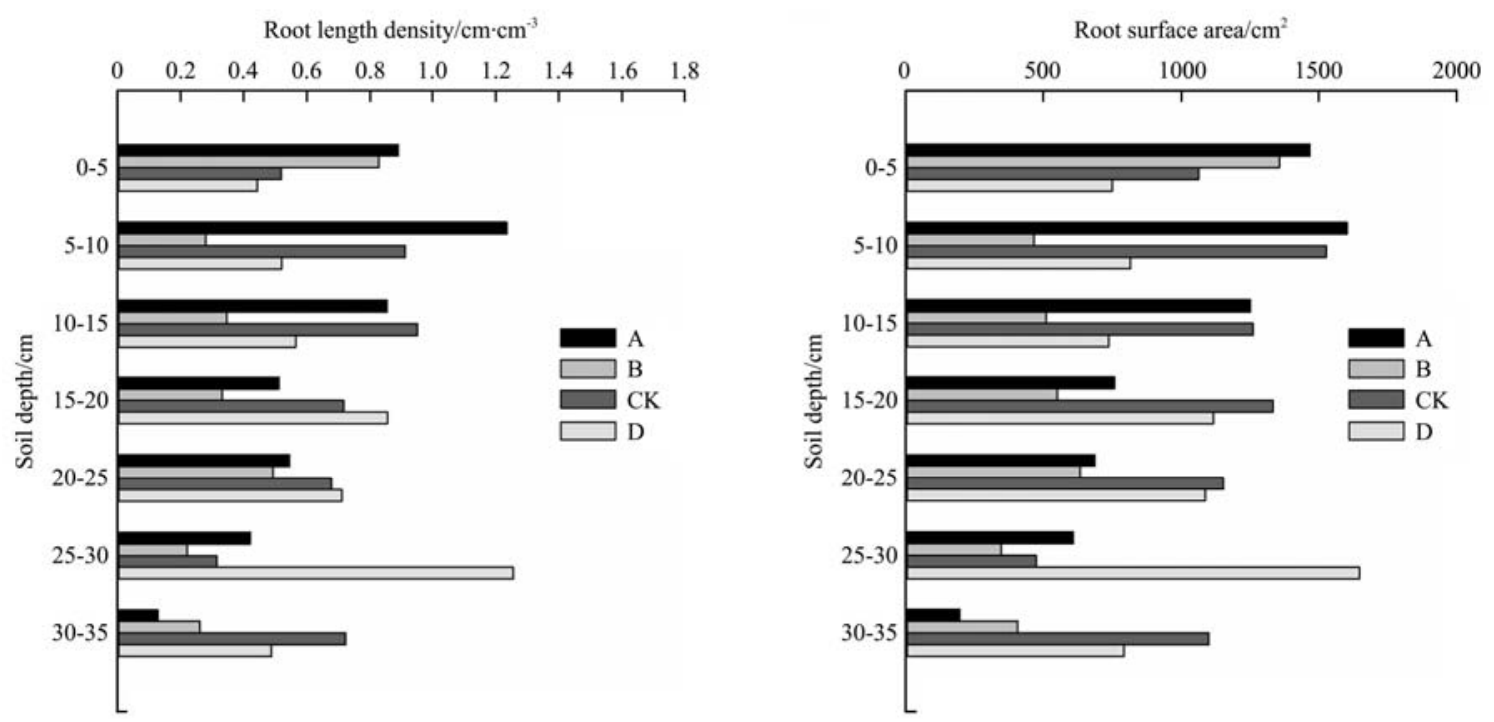

Figure 11 Root length density and root surface area at the maturity stage

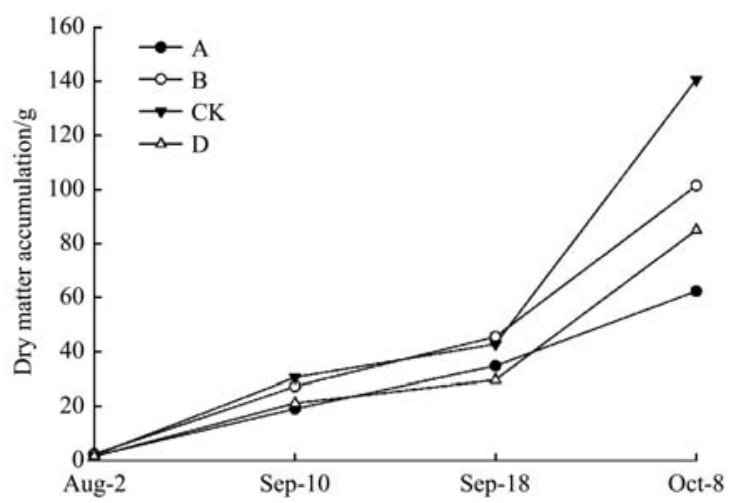

Figure 12 Dry matter accumulation in the different growth stages

\section{Discussions}

\subsection{Effects of different irrigation and fertilization regimens on soil moisture}

In terms of the soil moisture in the jointing stage, the root active layer was at the depth of approximately $0-20 \mathrm{~cm}^{[16]}$. Through the determination of the root, it is known that approximately $65 \%$ of the root distribution occured at a depth of 0-20 cm. CK treatment increased the deep depth of soil moisture and reduced the surface soil moisture. The A and D treatments increased soil moisture around the drip emitter (surface moisture) and reduced soil moisture at deep depths, which reduces the deep leakage of subsoil water. In the booting stage, the root active layers are at the depth of $20-40 \mathrm{~cm}^{[16]}$. The analysis of the root indicated that approximately $45 \%$ of the root was at the depth of 20-35 cm. The soil moisture of the B treatment, at the depth of 20-30 cm, was at a high level conducive to root water absorption. The soil moisture content of the CK treatment in this layer from the upper part of the soil to the lower part of the soil was maintained at a low level, which may allow for deep leakage of water flow out of the bottom of the pot. In the tasseling stage, CK treatment increased the soil water in the horizontal direction. Additionally, the water infiltration rate increased, but the soil water increased in the vertical direction, which also increases deep percolation. Furthermore, the A and B treatments were higher in surface soil moisture around the drip emitter and lower in deep soil water content, which reduces deep leakage and non-point source pollution. In the early grain filling stage, the soil moisture in each treatment was higher in the lower layer $(0-20 \mathrm{~cm})$, and decreased in the deep layer $(20-35 \mathrm{~cm})$. CK treatment showed little difference compared with $\mathrm{A}$ and $\mathrm{B}$ treatments. The $\mathrm{CK}$ treatment has higher moisture content than the $\mathrm{A}$ and $\mathrm{B}$ treatments, but only $10 \mathrm{~cm}$ horizontally away from the emitter. These results show that two irrigation methods can be used in this period.

\subsection{Effects of different irrigation and fertilization schedules on soil ammonium nitrogen and nitrate nitrogen}

From the determination of soil ammonium nitrogen and nitrate nitrogen content, it can be concluded that soil nitrate is not easily to be absorbed by soil colloids. Under the condition of sufficient water, it is easy to migrate with the water downward. After the application of nitrogen, soil nitrate nitrogen increased rapidly. Because of irrigation treatment and crop absorption, soil nitrate content accumulated in the deep soil layer ${ }^{[17]}$. This finding shows that under the base fertilizer, $50 \%$ of urea application in the jointing and booting stages is not conducive to improve the nitrogen utilization efficiency. The root system can affect the distribution of soil water and nitrogen in the $0-35 \mathrm{~cm}$ soil depth and reduces the two kinds of nitrogen in this soil layer depth. Preferential immobilization was found in the applied $\mathrm{NH}_{4}{ }^{+}-\mathrm{N}$ rather than the native $\mathrm{NO}_{3}^{-}-\mathrm{N}$ in the two kinds of nitrogen ${ }^{[18]}$. As seen in the jointing stage, the root active layer was at the depth of approximately $0-20 \mathrm{~cm}$. At this stage, the change of soil ammonium nitrogen and nitrate nitrogen in each treatment was very similar. The change was higher at the surface $(0-10 \mathrm{~cm})$ and deep $(20-35 \mathrm{~cm})$ layers, while the root was more active at the middle $(10-20 \mathrm{~cm})$ soil depth; ammonium nitrogen and nitrate nitrogen levels in this layer were low. CK treatment did not increase nitrate nitrogen and ammonium nitrogen in the jointing stage. A and D treatments showed lower levels of ammonium nitrogen and nitrate nitrogen in soil layers at the tasseling stage, and nitrogen content in the $\mathrm{CK}$ treatment increased, especially in deep soil layers. Furthermore, nitrogen content showed apparent downward leaching. In the booting stage, the nitrate nitrogen leaching in the CK treatment was more apparent; the nitrate nitrogen content increased in the CK treatment at the $25 \mathrm{~cm}$ depth, just below the emitter position. In the early grain filling stage, the nitrate nitrogen and ammonium nitrogen in the CK treatment were higher in the surface and deep soil layers, while the nitrogen in the middle layer was lower. Maize roots were largely distributed in the top $0-20 \mathrm{~cm}$ soil layer, with the proportion of roots in this layer 
observed as high as $68.7 \%$ and $77.6 \%$ in 2010 and 2011, respectively ${ }^{[12]}$.

\subsection{Effects of different irrigation and fertilization schedules on nitrogen use efficiency in each treatment}

In the jointing stage, observed from the nitrogen content in the pot, soil ammonium nitrogen and nitrate nitrogen was highest in the A treatment. In this stage, ammonium nitrogen and nitrate nitrogen were lower within the $0-20 \mathrm{~cm}$ layer of soil because of strong water and fertilizer absorption. The nitrogen content in the $20-35 \mathrm{~cm}$ was higher because the fertilizer migration with water to the deeper soil layer caused the deep seepage, which is not conducive to the absorption and utilization of crops. In the two growth periods of the booting stage and tasseling stage of maize which are the peak periods of water and fertilizer use, ammonium nitrogen and nitrate nitrogen was highest in the CK treatment, mainly in the soil depth of $20-35 \mathrm{~cm}$. The depth $(20-35 \mathrm{~cm})$ represents the crop root active layer, which can provide more nitrogen to the crop, allowing for crop growth and development. However, there may be higher distribution at the bottom of the soil layer and leaching of nitrogen away from the pot. In the early grain filling stage, the soil ammonium and nitrate nitrogen were highest in the $\mathrm{D}$ treatment, while the ammonium nitrogen and nitrate nitrogen in the soil layer first decreased and then increased. The nitrogen utilization rate of the A treatment was high, but the accumulation of dry matter showed a slow effect on growth. The nitrogen utilization rate of the D treatment was slightly lower than the A treatment, but the dry matter accumulation was higher than that of A treatment. Considering the utilization rate of nitrogen and dry matter accumulation, it appears that D treatment is beneficial to the utilization of nitrogen, and the supply is more in line with crop growth needs.

4.4 Effects of different irrigation and fertilization schedules on root length density and root surface area

Roots grow rapidly after the jointing stage, and the maximum root length is generally reached at the silking stage ${ }^{[19-21]}$. Root weight at harvest declined as $\mathrm{N}$ application increased but increased in response to $\mathrm{N}$ at two earlier sampling times ${ }^{[11]}$. With the exception of the $\mathrm{D}$ treatment, other treatments showed that the root length density and root surface area decreased gradually with increased soil depth at the seedling stage. At this stage, the roots of each treatment, which distribute in the $0-10 \mathrm{~cm}$ soil layer, were more than $40 \%$. In the jointing stage, all treatments of root length density and root surface area were first increased and then decreased with increased soil depth. The A and B treatments in this stage showed that the root was mainly located within the depth of $5-25 \mathrm{~cm}$; more than $80 \%$ of the root (Figure 17) was located at this depth. The depth $(20-35 \mathrm{~cm})$ represents the crop root active layer, which can provide more nitrogen to the crop, allowing for crop growth and development. Therefore, D treatment can increase the root length density of the deep layer, especially in the $20-35 \mathrm{~cm}$ soil depth, which is beneficial to the development of the root system. Meanwhile, A treatment may increase the root length distribution in the $0-20 \mathrm{~cm}$ soil depth at the jointing and booting stages.

In the tasseling stage, the CK treatment showed lower surface and higher bottom in root length density; root length densities of the other treatments were uniform in different soil layer depths, and the root of the CK treatment in the bottom at the depth of $20-35 \mathrm{~cm}$ was more than other treatments. The root growth in the other treatments was decreased to a certain extent in the deep soil layer, and increased root distribution was seen in the surface, especially in the $0-15 \mathrm{~cm}$ soil depth. In the booting stage, each treatment showed a fluctuation trend. Furthermore, root length density in the 30-35 cm depth of the CK treatment was higher than in other treatments. Therefore, the root surface area of the D and CK treatments is larger with increasing depth. These results show that both $\mathrm{D}$ and CK treatments can be used in this period.

\subsection{Effects of different irrigation and fertilization schedules} on dry matter accumulation

In terms of the dry matter accumulation, the trend of each treatment was from low to high. Before September $20^{\text {th }}$ (before the booting stage), each treatment showed few differences. In this stage, the B and CK treatments were higher than other treatments. After September $20^{\text {th }}$, the reproductive growth began to appear, showing differences between treatments. The CK treatment has the highest dry matter content, increased dry matter accumulation in the jointing and maturity stages of maize. The B treatment increased dry matter accumulation in the tasseling stage, and the dry matter accumulation of the remaining treatments were about half of the CK treatment. The reproductive growth had certain restrictions.

\section{Conclusions}

In the continuous irrigation method, water mainly affected the soil water in the vertical $35 \mathrm{~cm}$ depth. Continuous irrigation increased water content at the emitter position. Pulse irrigation had lower water content at the emitter position, which may be due to the large flow, allowing for water penetration into the deeper soil layer. From different fertilization treatments, it is found that D and B treatments were closer in nitrogen transport, which is beneficial to the absorption of nitrogen by roots, and reduced the deep leakage caused by the deep transport of nitrogen. In terms of the root distribution, continuous irrigation increased root growth in the early period of maize, namely, seedling and jointing stages of growth periods. Root growth of the CK treatment in this period under the condition of pulse irrigation was relatively slow.

The pulse irrigation increased the root development at the tasseling and booting stages because of certain water stress. The development was stronger in the deep layer at the tasseling stage. In the mature stage, A treatment had stronger root development in the surface layer, while D treatment had stronger root development in the deep layer. The nitrogen utilization efficiency of the A treatment was higher than other treatments, but the dry matter accumulation of the A treatment was at a low level in all treatments. Therefore, in the D treatment, no base fertilizer was supplied, and topdressing fertilizer at a ratio of $2: 4: 4$ was supplied instead in the seedling stage, jointing stage and tasseling stage, respectively. D treatment got second in nitrogen utilization efficiency, not only beneficial to the uptake and utilization of nitrogen by roots especially in the $20-35 \mathrm{~cm}$ soil depth, but also more conducive to the development of crop roots.

\section{Acknowledgements}

This research was funded by the Science and Technology Support Project (2014BAD12B06).

\section{[References]}

[1] Hanson B, May D. Effect of subsurface drip irrigation on processing tomato yield, water table depth, soil salinity, and profitability. Agricultural Water Management, 2004; 68(1): 1-17.

[2] Skaggs T H, Trout T J, Rothfuss Y. Drip irrigation water distribution patterns: effects of emitter rate, pulsing, and antecedent water. Soil 
Science Society of America Journal, 2010; 74(6): 1886.

[3] Badr A E, Abuarab M E. Soil moisture distribution patterns under surface and subsurface drip irrigation systems in sandy soil using neutron scattering technique. Irrigation Science, 2013; 31(3): 317-332.

[4] Ismail S M. Modeling the soil wetting pattern under pulse and continuous drip irrigation. American-Eurasian Journal Agricultural \& Environment Science, 2014; 14(9): 913-922.

[5] Phogat V, Mahadevan M, Skewes M, Cox J W. Modelling soil water and salt dynamics under pulsed and continuous surface drip irrigation of almond and implications of system design. Irrigation Science, 2012; 30(4): 315-333.

[6] Mansourifar C, Sanavy S A M M, Saberali S F. Maize yield response to deficit irrigation during low-sensitive growth stages and nitrogen rate under semi-arid climatic conditions. Agricultural Water Management, 2010; 97(1): 12-22.

[7] Ercoli L, Lulli L, Mariotti M, Masoni A, Arduini I. Post-anthesis dry matter and nitrogen dynamics in durum wheat as affected by nitrogen supply and soil water availability. European Journal of Agronomy, 2008; 28(2): 138-147.

[8] Azizian A, Sepaskhah A R. Maize response to different water, salinity and nitrogen levels yield-water relation, water-use and water uptake reduction function. International Journal of Plant Production, 2014; 8(2): 183-214.

[9] Liu J, Chen F, Olokhnuud C, Glass A D M, Tong Y, Zhang F, et al. Root size and nitrogen-uptake activity in two maize (Zea mays) inbred lines differing in nitrogen-use efficiency. Journal of Plant Nutrition \& Soil Science, 2009; 172(2): 230-236.

[10] Wang Y, Janz B, Engedal T, Neergaard A D. Effect of irrigation regimes and nitrogen rates on water use efficiency and nitrogen uptake in maize. Agricultural Water Management, 2016; 179p.

[11] Durieux R P, Kamprath E J, Jackson W A, Moll R H. Root Distribution of Corn: The Effect of Nitrogen Fertilization. Agronomy Journal, 1994; 86(6): 958 .
[12] Chen X C, Zhang J, Chen Y L, Li Q, Chen F J, Yuan L X, et al. Changes in root size and distribution in relation to nitrogen accumulation during maize breeding in China. Plant \& Soil, 2014; 374(1-2): 121-130.

[13] Zhang Y, Qing H D, Wu L M, Zhang J, Li Z, Huang M, et al. Growth characteristics and the effect of nitrogen application on the maize root. Journal of China Agricultural University, 2014; 19(6): 62-70. (in Chinese)

[14] Qi D L, Hu T T, Xue W, Niu X L. Rational irrigation and nitrogen supply methods improving root growth and yield of maize. Transactions of the CSAE, 2015; 31(11): 144-149. (in Chinese)

[15] Wen Z H, Shen J B, Blackwell M, Li H G, Zhao B Q, Yuan H M. Combined applications of nitrogen and phosphorus fertilizers with manure increase maize yield and nutrient uptake via stimulating root growth in a long-term experiment. Pedosphere, 2016; 26(1): 62-73.

[16] Zhu Y H, Yang P L, Du X, Liao R K. Exploration on the mechanism of super absorbent polymer effect on maize roots using stable deuterium and oxygen isotopes. Journal of Irrigation \& Drainage, 2016; 35(10): 42-46. (in Chinese)

[17] Liu X G, Zhang F C, Yang Q L, Tian Y F. Effects of controlled root-divided irrigation on transport and utilization of water and nitrogen in maize root zone soil. Transactions of the CSAE, 2009; 25(11): 61-66. (in Chinese)

[18] Azam F, Lodhi A, Ashraf M. Interaction of 15 N-labelled ammonium nitrogen with native soil nitrogen during incubation and growth of maize (Zea mays L). Molecular Microbiology, 1991; 31(6): 1709-1722.

[19] Lynch J P, Brown K M. Topsoil foraging - an architectural adaptation of plants to low phosphorus availability. Plant and Soil, 2001; 237(2): 225-237.

[20] Niu J F, Peng Y F, Li C J, Zhang F. Changes in root length at the reproductive stage of maize plants grown in the field and quartz sand. Journal of Plant Nutrition \& Soil Science, 2010; 173(2): 306-314.

[21] Peng Y F, Niu J F, Peng Z P, Zhang F S, Li C J. Shoot growth potential drives $\mathrm{N}$ uptake in maize plants and correlates with root growth in the soil. Field Crops Research, 2010; 115(1): 85-93. 